\title{
Does the weight of basketball shoes affect speed and jumping performance?
}

\author{
Köse B. ${ }^{\mathrm{ABCDE}}$
}

\author{
Department of Physical Education and Sport Teaching, School of Physical Education and Sport, \\ Sirnak University, Turkey
}

Authors' Contribution: A - Study design; B - Data collection; C - Statistical analysis; D - Manuscript Preparation; E - Funds Collection.

\begin{tabular}{|c|c|}
\hline \multicolumn{2}{|l|}{ Abstract } \\
\hline Purpose: & $\begin{array}{l}\text { The objective of this study was to analyze the effect of different weights of basketball shoes on speed and } \\
\text { jumping performance in male basketball players. }\end{array}$ \\
\hline Material: & $\begin{array}{l}20 \text { male basketball players in two groups, as eyes open ( } \mathrm{n}: 10) \text { and eyes closed ( } \mathrm{n}: 10) \text { participated in the study. } \\
\text { The two groups performed vertical jump (VJ) and } 10 \mathrm{~m} \text { sprint tests with three different weights of shoes (light, } \\
352 \mathrm{~g} \text {; medium, 510g; heavy, 637g). The data were analyzed with Friedman repeated measurements variance } \\
\text { analysis. }\end{array}$ \\
\hline Results: & $\begin{array}{l}\text { In Vertical Jump test, jumping performance of the eyes open group (EOG) with light shoes was found to } \\
\text { be statistically higher as } 1.8 \% \text { and } 2.1 \% \text {, respectively when compared with medium and heavy shoes ( }<< \\
0.001) \text {. In eyes closed group (ECG), no statistically significant difference was found between any of the } 3 \text { shoe } \\
\text { weights in vertical jump performance }(p>0.005) \text {. In } 10 \text { meter }(m) \text { sprint test, } 10 \mathrm{~m} \text { sprint time of the eyes open } \\
\text { group was found to be statistically better as } 0.5 \% \text { and } 1.6 \% \text {, respectively when compared with medium and } \\
\text { heavy shoe performance }(p<0.001) \text {. Medium weight shoe was found to be } 1.2 \% \text { statistically better than heavy } \\
\text { shoes ( }<0.001) \text {. In eyes closed group, light shoes affected } 10 \mathrm{~m} \text { sprint performance statistically better with } \\
1 \% \text { when compared with heavy shoes ( } p<0.001) \text {. }\end{array}$ \\
\hline Conclusions: & $\begin{array}{l}\text { Wearing light shoes in basketball has } 2.1 \% \text { and } 1.6 \% \text { positive effect on jumping and sprint performance, } \\
\text { respectively. It can increase basketball players' performance. Choosing light shoes will help provide both } \\
\text { psychological and physical advantages. }\end{array}$ \\
\hline 5: & Basketball, Dasketiall snoes, tootwear, jump, sprint. \\
\hline
\end{tabular}

\section{Introduction}

In basketball, approximately 997 to 1103 moves are made during a game [1]. This shows that about $22-25 \%$ of the game period consists of high intensity efforts such as jumps, technical explosive moves and short sprints [2]. In each of these high intensity efforts, players need to produce mechanical actions to speed up and suddenly slow down the mass of shoe [3]. One should think that light shoes have a positive effect on performance [4]. Hence, 100 gram decrease in weight decreases the metabolic cost and maximal oxygen consumption with a rate of $1 \%$. Wearing light shoes rather than heavy shoes has been shown to have physiological advantages such as low oxygen consumption and heart rate [5]. Similarly, Franz et al. showed that for each $100 \mathrm{~g}$ of mass added per foot, oxygen consumption increased by $0.92 \%$ and $1.19 \%$ during barefoot and shod running, respectively [6]. Within this context, since there are very few studies in literature in terms of effects of shoe weight on performance the aim of this study was to determine the effect of shoe weight on vertical jump and 10 meter sprint performance.

\section{Material and Methods}

Subjects. 20 male basketball players who were playing in the university basketball teams and who were having training at least 3 days a week (eyes open group: mean $\pm \mathrm{SD}$; age $21.8 \pm 3$ years, body mass $77.4 \pm 4.9 \mathrm{~kg}$, height $1.83 \pm 4.6 \mathrm{~cm}$; eyes closed group: age $22 \pm 1.9$ years, body

(C) Köse B., 2018

doi:10.15561/20755279.2018.0606 mass $78.1 \pm 3.6 \mathrm{~kg}$, height $1.82 \pm 4.9$ ) voluntarily participated in the study. Athletes who had lower extremity injuries at least for six months were not included in the study. The participants were told not to have intense training and use substances which are considered as ergogenic aid 48 hours prior to the tests. Care was taken to make the tests at a temperature of 23-24 degrees and at the same hour of the day. The study was carried out according to the ethical standards of the Declaration of Helsinki and has been approved by Sirnak University ethical board.

Study design. For the study, the weight of one shoe of each pair was determined as light (352 g), medium $(510 \mathrm{~g})$ and heavy $(637 \mathrm{~g})$. The intervals of shoe weights correspond to upper and lower limits of the existing basketball shoes [4]. The participants were randomly divided into two groups: eyes open (n:10) and eyes closed (n:10). The eyes open group was informed before each test to raise awareness. The eyes closed experimental group was not informed about the weights of shoes and the main idea of the study. The experimental group who were blindfolded during the tests was not allowed to lift and touch their shoes. The shoes were put on the participants by the same researcher during the whole experimental process. After the tests ended, the eye closed group was explained the purpose of the study. The tests were performed randomly in the sports hall with intervals of 24 hours. Randomization was required as it prevented the effect of adaptation and learning on athletes and thus results would be effected. The participants carried out the tests 3 times in total on different days. 
Experimental measurements. Before the tests, a 15-minute standardized warm up program was conducted and measurements were performed after a 5-minute rest. Vertical jump test was measured by using portable platform (Newtest Power Timer, Finland). The participants were asked to start the test as half squatting with a knee angle of $90^{\circ}$, with free hands and the body completely stable. While the hands of the participants swing up, they jump as high as possible by taking strength from their knees. Knees should not be bent at the moment of jumping. The participants should touch the ground on their heels and with their knees straight. Before the test, jumps were performed as a try-out 2 or 3 times at submaximal level. Later, 3 measurements were taken from each participant and the best result was recorded. $10 \mathrm{~m}$ sprint test was implemented by using photocell (Newtest Power timer, Finland). 2 photocells were put with a distance of $10 \mathrm{~m}$ for the test. The participants started to run from $1 \mathrm{~m}$ behind the start photocell and continued until the end of the second photocell. Before the measurements, necessary explanation was made to participants. The measurements were repeated 2 times with intervals of 2 minutes and the best result were assessed.

Statistical analysis. SPSS- 20 program was used for the analysis of data. The data of both groups were calculated with "Friedman Repeated Measurements Variance Analysis". In situations where differences were found as a result of "Friedman" test, "Wilcoxon Paired Sign Test" was used to find out which group caused the difference. $\mathrm{P}<0.05$ confidence interval was used for all statistical procedures.

Result

Vertical jump results are shown in Figure 1. Jump performance of EOG with light shoes $(50.95 \pm 2.36 \mathrm{~cm})$ was found to be statistically higher at a rate of $1.8 \%$ and $2.1 \%$, respectively when compared with medium $(50.04 \pm 2.28 \mathrm{~cm})$ and heavy $(49.92 \pm 2.26)$ shoes $(\mathrm{p}<$

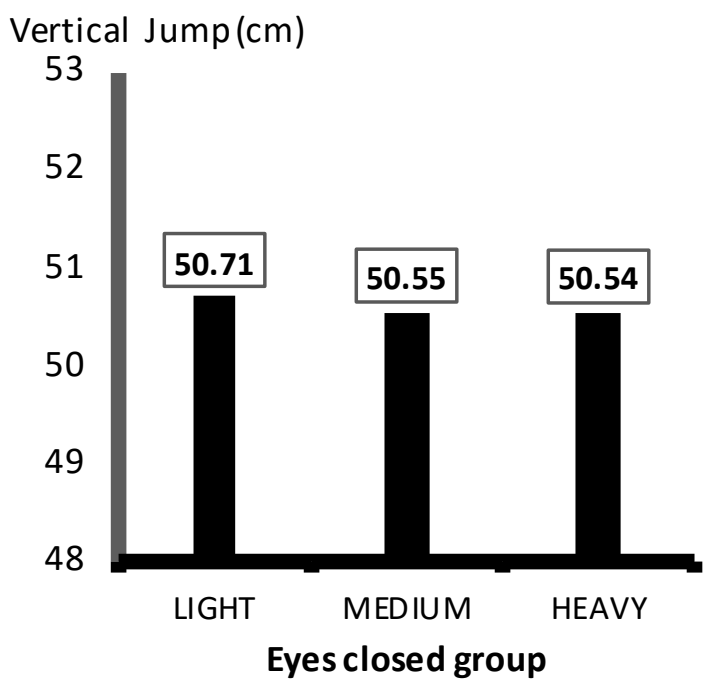

Figure 1. Jumping values of eyes open and eyes closed group with 3 different shoe weights. Asterisk mark significant differences between shoe conditions $(p<0.01)$. $\mathrm{cm}$ : centimeter.
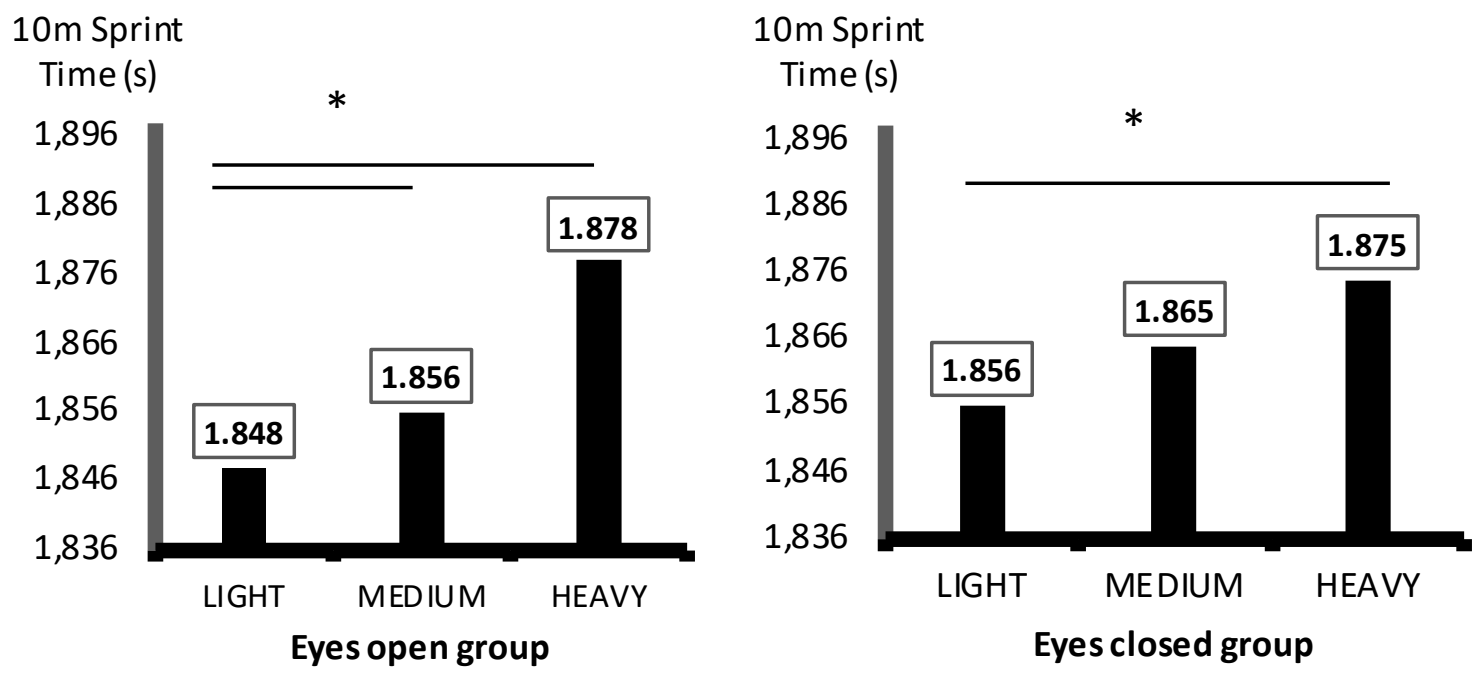

Figure 2. 10m sprint values of eyes open and eyes closed group with 3 different shoe weights.

Asterisks mark significant differences between shoe conditions $(p<0.01)$. s: Second 
$0.001)$. No difference was found between medium weight and heavy shoes $(\mathrm{p}>0.05)$. In vertical jump performances of EOG, no statistically significant difference was found between all three shoe weights (light, medium, heavy) ( $\mathrm{p}>$ 0.353).

Figure 2 shows $10 \mathrm{~m}$ sprint results. $10 \mathrm{~m}$ sprint results of EOG with light shoes $(1.848 \pm 0.28 \mathrm{~s})$ were found to be statistically better than the medium $(1.856 \pm 0.36 \mathrm{~s})$ and heavy $(1.878 \pm 0.40 \mathrm{~s})$ shoe performances with a rate of $0.5 \%$ and $1.6 \%$, respectively $(\mathrm{p}<0.001)$. Medium weight shoe was found to be $1.2 \%$ statistically better than heavy shoe $(\mathrm{p}<0.001)$. In the eyes closed group, light shoe $(1.856 \pm 0.18 \mathrm{~s})$ influenced 10 meter sprint performance statistically better than heavy shoe $(1.875 \pm 0.27 \mathrm{~s})$ with a rate of $1 \%(\mathrm{p}<0.001)$.

\section{Discussion}

The effect of different weights of basketball shoes on vertical jump performance was compared between two groups. One group was blindfolded and unaware of the weight of their shoes, while the other group knew that their shoe weights were different. In the study, light shoes of EOG were found to increase VJ performance with a rate of $1.8 \%$ and $2.1 \%$, respectively when compared with medium and heavy shoes. In the eyes closed group (EOG), shoe weight was not found to have an influence on jump performance. Eyes open group with light shoes showed a better jump performance. We believe that this created a placebo effect in performance since athletes' expectations against light and medium shoes resulted in positive and negative psychological factors, respectively. Mohr et al. compared jump performance in basketball players with heavy and light shoes. They reported that light shoes caused 2\% increase in eyes open group when compared with heavy shoes. They added that this increase resulted in psychologically positive and negative expectations for light and heavy shoes [4]. In another study, Blanche et al. reported that heavy shoes decreased jump performance [7]. Unlike Mohr et al. and Blache et al.; Worobets and Wannop reported that shoe weight did not increase jump performance in basketball players $[4,7,8]$. Jumps characterize one of the motoric features of a basketball player and in fact vertical jump ability is a very important component of performance in basketball [7]. Basketball players need to jump very quickly and to the highest point to get the ball from the basket before their opponents and to stop the opponent's ball. In the present study, increases were found in the performance of the group who were not aware of which shoe weight they jumped with. Increases were also found in the performance of the eyes closed group who did not know the shoe weight. These results showed how important psychological factors can be and that these psychological factors can affect physical parameters. Thus, as some of the studies conducted so far show that light shoe weight can increase vertical jump and thus can encourage basketball players to wear lighter shoes. Therefore, the belief of basketball players to have better performance by wearing light shoes may increase.
One of the remarkable results of the study was that basketball shoes with different weights affected $10 \mathrm{~m}$ sprint performance in both groups. The eyes open group was found to be statistically better than medium and heavy shoe performance with a rate of $0.5 \%$ and $1.6 \%$, respectively. Medium weight shoe was found to be $1.2 \%$ better than heavy shoe statistically. In the eyes closed group, light shoes were found to affect 10 meter sprint performance $1 \%$ better when compared with heavy shoe. Mohr et al. found 3\% performance difference in $10 \mathrm{~m}$ sprint time in both eyes open and eyes closed basketball players who wore light shoes when compared with those wearing heavy shoes. They stated that performance advantages of light shoes took place in the first two or three steps of sprint start. They also added that these advantages lasted until the end of 10 meters [4]. Vienneau et al. reported that basketball players who wore light shoes presented significant decreases in oxygen consumption and energy expenditure when compared with players who wore medium and heavy shoes [9]. Worobets and Wannop reported that shoe weight did not affect sprint performance in basketball players. They also stated that decreases in shoe weight did not have positive effects on performance. For these reasons, they concluded that it may not be a feature that should be taken into consideration while choosing shoes [8]. Although some studies other than basketball showed that light shoes increased running performance and decreased metabolic need [6, 10-12]. Some other studies reported that light shoes did not have an influence on running performance [13-17]. In the light of all these findings, it can be suggested that wearing light shoes in basketball can increase sprint performance.

\section{Conclusion}

As in all sport branches, the primary objective in basketball is to win as a team and to maximize individual performance. Since a game can be won within the last seconds of the game, seconds and even split seconds are very important in basketball game. Thus, basketball coaches should take into consideration every detail such as technical, tactical, condition, ergogenic aid, and placebo effect and want to get the maximum efficiency to maximize athletes' performance. The present study concluded that better jump performance of the eyes open group with light shoes created a placebo effect in their performance increase. The reason of this situation was that players' expectations against light and medium shoes influenced positive and negative psychological factors. In jump performance, it is thought that better performance of both groups with light shoes results from physical factors rather than psychological factors. The results obtained show that wearing light shoes in basketball has a positive influence of $2.1 \%$ and $1.6 \%$, respectively on both jump and short distance sprint performance. This can also improve the performance of basketball players. As a conclusion, preferring light shoes will help male basketball players to gain both psychological and physical advantage during the game. 


\section{Highlights}

This study is primarily relevant for coaches and basketball athletes. This study emphasizes the importance of a proper blinding of the research participants, as the results show that psychological factors affect performance outcomes.

\section{Acknowledgments}

The investigator would like to thank all subjects for

\section{References}

1. Abdelkrim NB, El Fazaa S, El Ati J. Time-motion analysis and physiological data of elite under-19-yearold basketball players during competition. British Journal of Sports Medicine, 2007;41(2):69- 75. https://doi.org/10.1136/bjsm.2006.032318

2. Abdelkrim NB, Castagna C, El Fazaa S, El Ati J. The effect of players' standard and tactical strategy on game demands in men's basketball. The Journal of Strength \& Conditioning Research, 2010;24(10): 2652- 2662. https://doi.org/10.1519/JSC.0b013e3181e2e0a3

3. Nigg BM. Biomechanics of Sport Shoes. University of Calgary; 2010.

4. Mohr M, Trudeau MB, Nigg SR, Nigg BM. Increased Athletic Performance in Lighter Basketball Shoes: Shoe or Psychology Effect?. International Journal of Sports Physiology and Performance, 2016;11(1): 74- 79. https://doi.org/10.1123/ijspp.2014-0538

5. Frederick EC, Daniels JR, Hayes JW. The effect of shoe weight on the aerobic demands of running. In: Bachl N, Prokop L, Suckert R. (Eds.) Current Topics in Sports Medicine, Proceedings of the World Congress of Sports Medicine. Vienna: Urban and Schwarzenberg; 1984. P. 616625 ,

6. Franz JR, Wierzbinski CM, Kram R. Metabolic cost of running barefoot versus shod: is lighter better?. Medicine \& Science in Sports \& Exercise, 2012;44(8):1519- 1525. https://doi.org/10.1249/MSS.0b013e3182514a88

7. Blache Y, Beguin A, Monteil K. Effects of various parameters of basketball shoes on vertical jumping performance: A case study. Science \& Sports, 2011;26(1): 48- 50. https://doi.org/10.1016/j.scispo.2010.08.007

8. Worobets J, Wannop JW. Influence of basketball shoe mass, outsole traction, and forefoot bending stiffness on three athletic movements. Sports Biomechanics, 2015; 14(3):351- 360. https://doi.org/10.1080/14763141.2015.1084031

9. Vienneau J, Tomaras EK, Nigg S, Nigg BM. Effect of their participation in this study.

\section{Financial support}

No financial support.

\section{Conflict of interest}

The author declares no Conflicts of interest concerning this article.

basketball shoes of different weights on performance in a game-like scenario. In ISBS-Conference Proceedings Archive, 2016;33(1):735-738.

10.Divert C, Mornieux G, Freychat P, Baly L, Mayer F, Belli A. Barefoot-shod running differences: shoe or mass effect?. InternationalJournalofSportsMedicine, 2008;29(6);512-518. https://doi.org/10.1055/s-2007-989233

11. Cheung RT, Ngai SP. Effects of footwear on running economy in distance runners: A meta-analytical review. Journal of Science and Medicine in Sport, 2016;19(3):260- 266. https://doi.org/10.1016/j.jsams.2015.03.002

12. Ayarra R, Nakamura FY, Iturricastillo A, Castillo D, Yanci J. Differences in Physical Performance According to the Competitive Level in Futsal Players. Journal of Human Kinetics. 2018;64(1):275-285. https://doi.org/10.1515/hukin-2017-0201

13.Sterzing T, Müller C, Hennig EM, Milani TL. Actual and perceived running performance in soccer shoes: A series of eight studies. Footwear Science, 2009;1(1):5- 17. https://doi.org/10.1080/19424280902915350

14.Menger B, Kannenberg A, Petersen W, Zantop T, Rembitzki I, Stinus H. Effects of a novel footankle orthosis in the non-operative treatment of unicompartmental knee osteoarthritis. Archives of Orthopaedic and Trauma Surgery. 2016;136(9):1281-1287. https://doi.org/10.1007/s00402-016-2500-2

15.Sharp JS, Poole SF, Kleiman BW. Optical Measurement of Contact Forces Using Frustrated Total Internal Reflection. Physical Review Applied. 2018;10(3). https://doi.org/10.1103/PhysRevApplied.10.034051

16.Ullah A, Shah M. Incapacitated decision making power, over emphasized obedience and its exclusionary effects on children. Journal of Social Inclusion. 2016;7(2).

17.Zhang HL, Cui XJ, Cao SL, Zhang Q, Sang SB, Zhang WD. Human Body as a Power Source for Biomechanical Energy Scavenging Based on Electrode-Free Triboelectric Nanogenerators. Energy Technology. 2018;6(10):2053-2057. https://doi.org/10.1002/ente.201800162

\section{Information about the author:}

Köse B. (Corresponding author); http://orcid.org/0000-0001-5315-9195; bereket.kose@hotmail.com; Department of Physical Education and Sport Teaching, School of Physical Education and Sport, Sirnak University; Mehmet Emin Acar Campus, 73000-Sirnak, Turkey.

Cite this article as: Köse B. Does the weight of basketball shoes affect speed and jumping performance?. Physical education of students, 2018;22(6):316-319. doi:10.15561/20755279.2018.0606

The electronic version of this article is the complete one and can be found online at: http://www.sportedu.org.ua/index.php/ PES/issue/archive

This is an Open Access article distributed under the terms of the Creative Commons Attribution License, which permits unrestricted use, distribution, and reproduction in any medium, provided the original work is properly cited (http:// creativecommons.org/licenses/by/4.0/deed.en).

Received: 04.09.2018

Accepted: 11.10.2018; Published: 26.12.2018 